\title{
Does ex ante application enhance the usefulness of LCA? A case study on an emerging technology for metal recovery from e-waste
}

\author{
Marco Villares $^{1} \cdot$ Arda Ișıldar $^{2} \cdot$ Coen van der Giesen ${ }^{1} \cdot$ Jeroen Guinée $^{1}$
}

Received: 9 August 2016 / Accepted: 10 January 2017 /Published online: 1 February 2017

(C) The Author(s) 2017. This article is published with open access at Springerlink.com

\begin{abstract}
Purpose A large proportion of the environmental impacts of a technology is determined by decisions made at the early development stages. Therefore, effective approaches to grasp the potential environmental performance of a technology early in development are needed. This paper reflects on the usefulness of ex ante application of LCA using a case study on the appraisal of the potential environmental impacts of a lab-scale novel process for bioleaching of e-waste for metal recovery. Methods The LCA framework was applied at an early stage to the novel bioleaching process to embed it in a life cycle context, linking it to upstream and downstream flows. Then, a short-term future scaled-up scenario was defined using a proxy technology and estimated data. Environmental hotspots of this scenario were identified, and its environmental impacts were compared with those of a current industrial pyrometallurgical technique, involving an integrated smelter refinery. Results and discussion LCA displays potential environmental hotspots related to energy and material inputs for the bioleaching process and solvents for copper recovery, despite uncertainties. Comparison with an existing integrated smelter refinery technology returned an inferior environmental
\end{abstract}

Responsible editor: Roland Hischier

Electronic supplementary material The online version of this article (doi:10.1007/s11367-017-1270-6) contains supplementary material, which is available to authorized users.

Jeroen Guinée

guinee@cml.leidenuniv.nl

1 Institute of Environmental Sciences (CML), Leiden University, Van Steenisgebouw, Einsteinweg 2, 2333 CC Leiden, The Netherlands

2 UNESCO-IHE Institute for Water Education, Westvest 7, 2611 AX Delft, The Netherlands performance. These results could not be considered accurate given the early-stage application, yet they served as valuable preliminary information. The uncertainties also prompted further enquiry about the chosen product system boundary, the role of the emerging technology and the comparability of the technologies.

Conclusions The ex ante application of life cycle assessment on an emerging technology brings a systematic rigour and discipline to an ambiguous situation at the start of technological development. Applying the LCA framework broadens the scope of the research, introducing a systems approach and long-term view. Environmental aspects and alternative perspectives on the novel technology are also brought into the research domain. The approach creates new knowledge on the novel technology's potential development, and developmental challenges are given definition at an early stage.

The LCA outcomes should not be regarded as a final result but have a signalling purpose as a contribution to technological development. Though imprecise with much conjecture involved, such an approach gives a valid mock-up of a plausible future providing useful provisional insights to be built upon. Applying ex ante LCA and an exploratory scenario to an emerging technology is of great service as a developmental design tool and can be further refined in later development stages.

Keywords Development · Ex ante $\cdot$ Exploratory scenario · LCA $\cdot$ Life cycle assessment $\cdot$ Scaling $\cdot$ Technology

\section{Introduction}

The design phase of a product, when its essential characteristics are defined, is the most important phase in its life cycle, particularly with regards to future consequences for 
functionality, cost and environmental impact. Decisions made at this stage, where around $70 \%$ of the final cost, functional requirements and environmental impacts are determined, will have far reaching influence later (Jeswiet and Hauschild 2005). What holds true for product design is broadly backed up for the design and development of most technologies in general (Andreasen 1991; Boothroyd et al. 2000; Nielsen and Wenzel 2002; Korevaar 2004; Duflou and Dewulf 2005; Dewulf et al. 2006; Graedel and Allenby 2010). Finding an effective initial concept to inform a novel technology at the start is most important to determine its eventual cost and to minimise environmental impacts. What Andreasen (1991) calls 'provident thinking' is required in the early stages of the design to look at and react to the consequences for the product or technology during the later phases of its life cycle.

Trends are observable in technological development, but predicting where future technological changes will occur is difficult. Predicting their associated potential, future environmental impacts is even more difficult (Simon 1969). Providing some reasonable consideration and appraisal of environmental impacts as early as possible in technological development is necessary, given the high degree of influence in such outcomes of this phase.

Life cycle assessment (LCA) can play a role in supporting this appraisal. It has a long track record as an effective multicriteria environmental assessment tool since it was introduced in the late 1960s (Guinée et al. 2011). However, LCA is predominantly applied to existing products and services and is thus retrospective in nature. It has shortcomings that diminish accuracy and increase the uncertainty of assessment results. Reap et al. (2008) list problems in all LCA phases with functional unit definition, boundary selection, allocation, spatial variation, local environmental uniqueness, and data availability/quality. Ways that uncertainty has been acknowledged involve replication of LCA using scenarios where assumptions are changed one at a time to compare different outcomes (Clavreul et al. 2012), exploring and reporting the sensitivity of the LCA outcomes to changes, and applying and incorporating statistical uncertainty analysis (Henriksson et al. 2013).

The implicit demands of effective application of ex post LCA are magnified in ex ante applications due to the lack of definition of the product system when more and different uncertainties are involved, and this calls for extra vigilance (Hospido et al. 2009; Hetherington et al. 2013). Main problems can emerge from three areas: difficulties in defining the goal and scope of the LCA at such an ex ante stage; uncertainty involving the process data which may be lacking and of poor quality, resulting in dubious potential environmental impacts; and the establishment of an accurate level of confidence in data interpretation (Cinelli et al. 2014). Nonetheless, attempts have been made to apply the tool to emerging technologies where requisite information for modelling is limited.
Such approaches typically involve scaling up the technology, using scenarios based on estimates or simulations of enhanced yields at production scales, where the associated production maturity and efficiency brings more environmental benignity (Gavankar et al. 2015).

Since most of the environmental impacts are determined at the early development stage (Tischner et al. 2000), there is a mismatch with the capability of the available environmental analysis tools. Identifying the differences between laboratory systems and industrial processes is crucial to establish data validity. Lab-scale experiments are typically done in batches and are less efficient having lower yields than typical continuous industrial-scale processes where efficiency gains have been integrated (Frischknecht et al. 2009). Scaling up can uncover by-products such as wastes, heat and wastewater (Shibasaki et al. 2007b). Also, small variations in lab measurements or from model simulations may be amplified to large data errors. The impacts of specialised equipment and instrumentation used in the lab and without obvious larger-scale industrial equivalents may also be underestimated (Hetherington et al. 2013).

Data uncertainty at the laboratory level is combined and aggregated with other heterogeneous data during LCA analysis. Further scaling up of the LCA modelling amplifies imprecisions, uncertainties and variabilities bringing into question the validity of the results even more. As Hetherington et al. (2013) describe, a novel technology at lab scale will be less complex and have lower yields than a commercial-scale process and because of the scale difference will not be comparable. To address these issues in the LCA modelling, her team suggests using process simulation and engineering design to generate data at different scales, using estimative future scenarios applying economic input/output models to obtain national average data. Also, the reporting of iterative LCAs generated as new processes are developed is encouraged. According to Hetherington et al. (2013) such limitations should be recognised and made explicit to all stakeholders involved.

This does not negate the value of exploratory studies which can be later added to and corrected cumulatively by further research in later development stages (Nielsen and Wenzel 2002). Ultimately, it is important to recognise that the outcome of an LCA is not an absolute result. The value of LCA lies in its application to comprehensively compare systems, and its outcomes are useful in a relative sense in spite of the uncertainties. Moreover, it may also be argued that the known limitations of LCA instil a rigorous approach, compelling the practitioner to maintain focus, dismiss complacency, remain alert and report the 'what-ifs' in a transparent manner.

This paper will examine the usefulness of the application of ex ante LCA by reflecting on the results of a case study previously performed by Villares et al. (2016). Here, an extensive discussion of the approach behind the previous case study article will be carried out. A full-blown new method that is 
proven to work is not presented here, rather an exploration of new possibilities requiring further development.

The case study sought to evaluate the potential environmental impacts of a laboratory-stage novel bioleaching technology for the recovery of metals from electronic waste. Discarded electrical and electronic equipment is a growing waste stream becoming more problematic in its management. Unsafe disposal contributes to environmental pollution, threatens human health and wastes secondary resources (Ongondo et al. 2011). The recovery of valuable metals from electronic waste can be achieved by bioleaching, a biologically mediated natural chemical process where, in an acidic aqueous medium, metal-resistant bacteria act as a biocatalyst accelerating the dissolution of metals (Brandl et al. 2001; Erüst et al. 2013). Bioleaching bacteria can work at near ambient temperatures and generate few direct contaminants, compared to metal recovery using smelting at high temperatures (Vera et al. 2013). Initial bioleaching experiments of metal recovery from electronic waste show efficient yields with $98.4 \%$ copper removed (Ișildar et al. 2015). The bioleaching process is considered a promising emerging technology contributing to secondary resource recovery relevant in the context of a transition to a more environmentally friendly circular economy (Hennebel et al. 2015). However, claims of benign environmental performance in the research literature are only based on process-centric suppositions, considering the steps of the metal recovery process alone, and do not take into account a life cycle perspective.

Following this introduction, Sect. 2 briefly describes how LCA was applied in the case study. Then, the case study itself is summarised with an overview of the main LCA results. In Sect. 4, how the LCA results influenced subsequent research is discussed. There is also a broader reflection and evaluation of the whole exercise of the case study and the implications for the usefulness of LCA. Sections 5 and 6 round up with conclusions and some recommendations.

\section{Methods}

The previous paper by Villares et al. (2016) describes the cumulative research approach and the results of how the labscale metal recovery process using bioleaching was embedded in a larger product system incorporating upstream and downstream processes. This lab-scale system is not comparable with an industrial-scale system. Since the novel bioleaching process is aimed at future scaling up for industrial use, a second stage involved modelling this by building on the findings of the first stage. In order to do this, a scenario approach was used to determine a plausible commercial-scale system. Then, in a third stage, its environmental performance was compared with a traditional pyrometallurgical technique (an integrated smelter refinery), in order to further explore its feasibility.
The approach followed some of the guidelines for ex ante LCA recommended by Hospido et al. (2009). The LCAs were forward looking and descriptive, 'prospective attributional LCAs'. The foreground system was modelled with specific data, while the background system used average data from ecoinvent database v2.2. System boundaries excluded unit processes not affected by the novel process constituting what Guinée et al. (2002) call a 'difference analysis'.

\section{Summary of cumulative LCAs}

The four phases of the life cycle assessment framework were applied to the product systems at different development phases (Guinée et al. 2002; International Organisation for Standardization (ISO) 2006). Goal and scope definition, life cycle inventory (LCI), life cycle impact assessment (LCIA) and interpretation were applied in three stages: stage 1, stage 2 and stage 3 .

\subsection{Stage 1: attributional LCA}

In the first stage, the goal of the attributional LCA performed on the lab product system was to carry out a general preliminary exploration and to identify potential hotspots. Using primary data provided by lab experiments, the laboratory process of metal recovery from printed circuit boards (PCBs) by bioleaching was modelled, complemented with estimates derived from literature and proxy substances adapted from the ecoinvent database where data was unavailable. The function of the product system was the recovery of elementary copper from electronic waste, with a functional unit of $1 \mathrm{~kg}$ of recovered elemental copper from printed circuit boards separated from electronic waste at the plant gate.

The product system has three main unit processes starting with pre-treatment of the high-grade electronic waste (printed circuit boards) by crushing and pulverising. The resulting powder is added to a bacterial culture previously inoculated with mineral salts, which act on it mobilising the metals to solution. There was only partial primary data going up to the bioleaching stage, so to achieve elemental copper recovery, the last unit process of solvent extraction (SX) and electrowinning (EW) was added using literature data and estimates. Solvent extraction concentrates the copper in the leachate solution using a solvent to isolate it, making it suitable for electrolytic copper recovery. No data was available for the treatment of a solid residue of bioleaching, so this was cut off.

In the lab product system, the bioleaching unit process was the dominant contributor in all impact categories. This was due to the size of the pregnant leachate solution (PLS) economic flow, which in the LCA model increases 300-fold to feed the SX-EW step. This was attributed to a mismatch in efficiencies reflected in the modelling of the lab system connecting of the 
rates of lab bioleaching (batch) from primary data and the SX-EW (continuous) processes from industrial data.

\subsection{Stage 2: prospective attributional LCA}

The goal of the LCA of the scaled-up system is to establish a plausible environmental profile of the latter for comparison with that of an existing best available technology. Due to the scale, the results of the lab-scale LCA of stage 1 were unsuitable for comparison with an industrial-scale system. Stage 1 was built upon in stage 2, where the laboratory system was enlarged to an industrial size applying an exploratory 'whatcan happen' scenario (Höjer et al. 2008) with a short-term view, focussing on the effects of different internal design decisions to be taken in future development of the technology. This involved the least complexity and uncertainty, allowing the reasonable use of background data two decades old from the ecoinvent database. The age of the data is considered less relevant for comparative purposes at this early stage and may be updated later.

To develop the scenario, two techniques briefly outlined in the following two subsections were referenced: how the scaling up of novel technologies can be addressed and a design approach to collect and analyse contextual background information to then define a scenario.

\subsubsection{Development of scenario: scaling issues in technology development}

Scaling up can be approached as practical enlargement purely focussing on the product system at hand. Some researchers have investigated this from an engineering perspective to provide guidelines for making assumptions when scale is increased. Diverse technological scales can be distinguished as shown in Table 1.

As development progresses, the inputs and outputs of a product system can be influenced by changes in yield, energy efficiency and supply, as well as the amount of waste and emissions generated. From these general heuristics of scaling up, Shibasaki et al. (2007a) propose doing a systematic target-oriented relevance analysis to identify the aspects of the future product system likely to have the largest influence on the LCA outcome, excluding those with the least expected impact. In such an analysis, optimisation factors can be applied to those unit processes with greatest relevance assuming more efficiency (e.g. reduction of energy requirements).

These factors can be derived from empirical statistical data, exemplified by the study by Caduff et al. (2014) on the effects of scaling on pumps and biomass furnaces. The latter study also found that if the cost scaling factor for equipment is based mainly on material input and utility supply, it can be a good indicator for the scaling factor used in the LCA. The application would be similar for concept screenings and initial project appraisals. The study represents a first step in the direction of parametrisation of unit process data, which is useful to enable more robust estimative modelling of scaled-up technologies in LCA. Piccinno et al. (2016) have also contributed an engineering-based framework that helps to scale up earlystage laboratory chemical production processes for LCAs following a systematic procedure based on estimates. They looked at heated liquid phase batch reactions, identifying and simplifying the most important calculations for the reaction step's energy use as well as for certain purification and isolation steps.

This brief review highlights the relationship between scale and technology development with techniques that assume a particular development path that has a certain degree of engineering predictability. When faced with a feasibility evaluation at the initial stage, as in this case study, there is no chosen development path. Then, during the definition of a plausible future scenario, the importance of which order of magnitude of scaling is made becomes a relevant choice as the path underlying the scenario choice(s). In this case, the practitioners could choose a scenario ranging between small, flexible modular, even mobile, bioleaching plants to large facilities, dependent on bulk volume feed stocks, at the smelter scale. Comparability with the existing technology was an essential concern, and to make an informed choice, more contextual information was required.

\subsubsection{Development of scenario: applying design thinking tactics}

The methodical, procedural engineering approach was supplemented with more exploratory background information to enrich the context and give more foundation to the scaled-up
Table 1 Plant scales from development to production (adapted from Shibasaki, Warburg and Eyerer 2006)

\begin{tabular}{ll}
\hline Scale & Characteristics \\
\hline $\begin{array}{c}\text { Laboratory } \\
\text { scale }\end{array}$ & Used to determine process behaviour and conditions \\
Mini plant & Size remains lab scale but with conditions set as basis to replicate a future production plant \\
Pilot plant & Small-scale production plant to generate information for production plant and its optimisation \\
$\begin{array}{c}\text { Production } \\
\text { plant }\end{array}$ & $\begin{array}{c}\text { Economically viable plant with economies of scale, optimised production capacity and process } \\
\text { synergies }\end{array}$ \\
\hline
\end{tabular}


scenario. This investigative, exploratory approach is derived from design methodology where a thorough grounding in the context of the design requirements is usually carried out to consciously and unconsciously supply clues for satisfactory design solutions from a typically ill-defined problem (Cross 2005). Since a design is typically considered as the response to a specific problem, the context of the problem does need to be comprehensively understood to arrive at any kind of plausible design solution. Often, this modus operandi can go 'in reverse' and even questions the way the problem has been formulated and then back again. This is recognised as the coevolution of the 'problem-solution space' (Dorst and Cross 2001). Problem and solution are not considered separate entities but are accepted as interrelated. In this space, multi-directional, iterative cognitive processes are carried out by the practitioner that also require connection to external resources. Using only internal mental processes is insufficient; the designer needs to interact with some sort of external representation with heightened awareness of any unexpected opportunities or vantage points and to observe promising fruitful ways forward (Cross 2011). The practitioner also accepts concepts of incompleteness, vagueness or ambiguity, at the same time managing likelihood and expectation (Haupt 2014).

In this uncertainty-laden problem-solution space, there is room for testing and measurement but also intuitive judgements returning speculative solution concepts with emergent properties. These properties are perceived in a partial solution, or a prior solution, that were not consciously included or intended. The latter can afford indications of how the developing solution concept might be aligned with the also developing problem concept (Cross 2011). Making solution conjectures is often a way to clarify the design problem (Cross and Roozenburg 1992).

This deliberate human agency has been recognised in the development of all technology, where the term technology refers to a means of fulfilling a purpose, reliably exploiting some usable natural effect (Arthur 2007). The design process, involving recursive problem solving, can be triggered by some purpose, need or limitation that becomes the design problem. Design processes, though sometimes highly non-linear, can often be broken down into phases or steps. Essentially, they are the process of translation of function into form (Korevaar 2004). They involve the basic cycle of design, which is the natural, cyclic way of problem solving. In this cycle, after exploration, solutions for the design problem are generated, evaluated and communicated (Cross 2005). A generic design process outline would include problem definition, research, ideation, prototyping, selection of solutions, implementation and learning (Ambrose and Harris 2009). In some design areas such as architecture, where the scale of the targeted solution is almost always too large to test and prototype, the definition and research steps are crucial (Andreasen 1991; Andreasen 2011). They will involve the thorough investigation of precedents in the search for archetypal patterns and clues to inform the creation of the development path (Oxman 1994). In such cases, such a strategy is an indispensable form of knowledge gathering and a way to progress within the problem-solution space. Design research involves indispensable analysis of existing designs or precedents in order to acquire typological knowledge and insights applicable for design development (Nijhuis 2011).

\subsubsection{Development of scenario: contextual underpinning of scenario choice}

In light of this, the scaled-up scenario was informed by important contextual considerations when addressing the developmental future of bioleaching applied to waste electrical and electronic equipment (WEEE) as a metal recovery technology. This encompassed a review of present WEEE regulations in Europe and how WEEE is recycled. Additionally, the direction of current bioleaching research was reviewed to appraise expected developments. For example, a lab study by Ilyas and Lee (2014) describes the promising performance of a 2-1 stirred tank bioleaching reactor with an accompanying report on possible operational economic feasibility. All of the above were considered to inform the choice of pathways for the plausible development of bioleaching applied to metal recovery from WEEE.

One of the most informative areas for this purpose was bioleaching techniques already applied for primary metal recovery at larger scales by the mining industry (Brierley and Brierley 2013). Existing technologies for metal recovery from mineral ores used by the mining industry are large-scale smelters (pyrometallurgy) or large-scale hydrometallurgical and biohydrometallurgical applications. The bulk scale of the raw material inputs determines the most efficient size and volume of the technology. The industries seek economies of scale with large inputs of mineral ores typically sourced in remote uninhabited areas as an established part of the supply chain.

\subsubsection{Development of scenario: existing bioleaching technologies}

Heap bioleaching extracts solubilised metals from mounds of irrigated low-grade mineral ores already inoculated with indigenous bacteria. Movement and processing of large quantities of massive materials and careful engineering, monitoring and maintenance of the heaps to ensure good performance are required. The pregnant leaching solution is recycled, and air has to be propelled deep into the heaps with ventilators to provide the bacteria with oxygen and carbon dioxide. Large quantities of water and sulphuric acid are required. At the start, months are needed before a significant yield is achieved, but 
once in operation metal recovery does become a continuous process (Biswas and Davenport 2011).

Continuous stirred tank reactors (CSTRs) can be considered a contained and concentrated version of heap leaching, requiring more processing, with more water going through the system and working at a higher speed. This can also be thought of as a more direct scaled-up version of the shake flask lab process. CSTR can flexibly process lower-grade bulk amounts, are tolerant to impurities and allow the recovery of precious metals in contrast to smelting. The technology can be implemented in a modular fashion and is less sensitive to economies of scale than smelting. However, it needs a large size of high-quality equipment and is energy-intensive so generally it is not cost-competitive with smelting (Neale et al. 2009).

\subsubsection{Chosen plausible scenario}

In light of the above, in contrast to mineral ores, WEEE is a large but dispersed waste stream sourced from urban areas, requiring concentration and then sorting for metal recovery. Heap bioleaching is less appealing for application to electronic waste, requiring a larger area and presumably meeting social resistance in proximity to urban areas. Quantitative estimations were made of the expected WEEE and printed circuit board input to be processed at the European level, and this suggested less electronic waste input for the technology when compared to mineral ore streams. Thus, this pointed to a plausible medium scale such as that of a waste management plant. Rather than a stand-alone large-scale facility, a bioleaching plant with CSTR can be conceived as an extension of existing waste management, waste to energy and composting plants. A bioleaching plant could be incorporated on the sites of such facilities. In the Netherlands, due to waste management regulation (e.g. limiting landfilling), such plants manage diverse types of wastes and are also active in energy production, bioconversion, digestion and material separation.

Therefore, secondary metal recovery using biotechnology can be a natural expansion of such a material processing centre. For example, the waste management plant at Moerdijk in NL separates ferrous as well as non-metals in a special facility for that purpose (Attero website 2015). Such facilities are at a suitable intermediate scale and at locations between global commercial-scale mining and the poles of urban WEEE generation and could accommodate secondary metal recovery. The physical proximity of diverse waste treatment functions also provides potential for incorporating industrial symbiosis synergies between processes. The technology is a novel application of existing processing techniques, in essence a technology transfer, and as such could be set up quickly in a modular fashion as evidenced in the HydroWEEE pilot project (Rocchetti et al. 2013), which is an example of a mobile hydrometallurgical plant. The scenario is summarised in Table 2 (for more details, see also the Supplementary Information).
For LCA modelling of a PCB bioleaching CSTR facility as the extension of an existing waste management plant in an industrial cluster in the Netherlands, the three steps of the lab product system were maintained. However, now pre-treatment was substituted for a mechanical shredding process from the ecoinvent database and the bioleaching and SX-EW data came from the conceptual engineering study for a mineral ore bioleaching process used as a viable proxy (Neale et al. 2009). This model processes the same amount of input using CSTR but uses different bacterial strains operating at higher temperatures.

The LCA results showed that the bioleaching and SX-EW unit processes are the largest contributors to the potential environmental impacts of the scaled-up product system. Neglecting the large input from the pregnant leachate solution (PLS), a breakdown of the SX-EW unit process confirmed the largest contributor to be the SX solvent, derived from petrochemicals. Across all impact categories, the relative impact of mechanical shredding was negligible.

\subsection{Stage 3: comparative attributional LCA}

In the third stage, an environmental impact performance comparison of the scaled-up product system with a contemporary industrial pyrometallurgical technique was carried out. The pyrometallurgical system, roughly modelled in the ecoinvent database, has two unit processes. First, PCB, which is a high-grade ewaste, goes directly to the smelter's converter. Then, in the second unit process, it is refined to cathode-grade copper.

Before the comparison, an optimisation was carried out on the scaled-up product system, which can be considered a sensitivity analysis. It simulated a simple process intensification by increasing the amount of processed PCB from 1 to $10 \%$ and the theoretical maximum of $20 \%$, with all other parameters remaining the same. No anomalies were observed, and the LCA model scaled linearly. The LCA model also responded in the same way to small perturbations.

The comparison of the environmental profiles showed a considerable order of magnitude difference, ranging from 2 to 5 , between the potential impacts. Even after the simulated optimisation, the scaled-up emerging technology displayed an inferior environmental performance.

For further information on the LCAs and how the scaled-up scenario was defined and the LCAs, see the Supplementary Information.

\section{Results and discussion}

In the LCAs of stage 1 (lab-scale) and stage 2 (scaled-up scenario), potential hotspots were identified in the energy and material inputs for the bioleaching process and solvents for copper recovery. The comparison with the existing technology returned a far inferior environmental profile, even after 
Table 2 Summary of scenario information

\begin{tabular}{|c|c|}
\hline \multicolumn{2}{|c|}{ Current contextual aspects for scenario } \\
\hline European regulations & $\begin{array}{l}\text { Waste electrical and electronic equipment (WEEE) directive 2012/19/EU } \\
\text { Restriction of Hazardous Substances (RoHS) directive 2011/65/EU } \\
\text { Registration, Evaluation, Authorisation and Restriction of Chemicals } \\
\text { (REACH) regulations (EC 1907/2006) }\end{array}$ \\
\hline Metal recycling techniques & $\begin{array}{l}\text { Mechanical pre-treatment, hydrometallurgical (acid and caustic leaching) } \\
\text { and/or pyrometallurgical (smelting) combined with electro-refining }\end{array}$ \\
\hline $\begin{array}{l}\text { Current bioleaching research on } \\
\text { WEEE }\end{array}$ & $\begin{array}{l}\text { Chiefly bench top and batch processing in open shake flasks, column } \\
\text { bioleaching } \\
\text { Lab-scale continuous stirred tank reactor }\end{array}$ \\
\hline $\begin{array}{l}\text { Similar industrial-scale } \\
\text { bioleaching technologies }\end{array}$ & $\begin{array}{l}\text { Bioleaching of low-grade mineral ores in situ, heap and dump leaching, vat } \\
\text { leaching and continuous stirred tank reactors (CSTRs) }\end{array}$ \\
\hline Scenario estimates and assumptic & s for future development \\
\hline $\begin{array}{l}\text { Estimated WEEE generation in } \\
\text { Europe }\end{array}$ & $\begin{array}{l}\sim 12 \text { million tonnes/year of WEEE, of which } 65 \% \text { considered collected anc } \\
\text { recycled according to EU target, resulting in } \sim 7.8 \text { million tonnes }\end{array}$ \\
\hline $\begin{array}{l}\text { Estimated PCB and recoverable } \\
\text { copper }\end{array}$ & $\begin{array}{l}\sim 2.5 \% \text { of WEEE is PCB: } \sim 200,000 \mathrm{t} / \text { year of which } \sim 20 \% \text { is copper, } \\
\text { resulting in } 40,000 \mathrm{t} / \text { year of copper }\end{array}$ \\
\hline Chosen proxy technology & $\begin{array}{l}\text { Fast and controllable plant with continuous stirred tank reactors with } \\
\text { capacity to treat } \sim 100,000 \text { t/year (half the amount generated) } \\
\text { Data used from model of integrated bioleaching and SX-EW production } \\
\text { plant designed to process } 10 \% \text { of mineral concentrate using thermophile } \\
\text { bacteria }\end{array}$ \\
\hline
\end{tabular}

further optimisation. These results could not be considered accurate given the precociousness of application, yet valuable information was generated. The uncertainties also prompted further enquiry about the system boundary, the role of the emerging technology and the comparability of the product systems. The following sections will give an overview of how the approach provided valuable insights for further technological development.

\subsection{Improving bioleaching technology}

Where the lab research is at a stage not much further than the design of experiments to characterise the bioleaching process and improve metal recovery yields, scaled-up LCA modelling and interpretation showed that water was the predominant material going through the product system compared to the bacteria and metals. The precise method of elemental metal recovery had not yet been considered nor experimented on so this also became part of the discussion. A precipitated intermediate product and electrowinning were considered, with the latter being chosen for LCA modelling as the most direct way to obtain the elemental metal.

In the next development cycle, the recycling of process water and sulphuric acid and alternative feedstocks with less potential environmental impact such as biogenic sulphur and the minimisation of waste can be studied. At the level of the process equipment, the bioreactor design can be developed targeting the lowering of its energy requirements.
The simulated process intensification of the scaled-up system with increased pulp densities to give improved copper recovery provided a rough situating strategy. It spurred broader thinking regarding its possible future optimisation at the level of the process itself. More ideas for optimisation in the scaled-up context followed such as the adaptation of the micro-organisms and exploring natural bacterial consortia that work more efficiently. As the mechanisms of bioleaching itself are not well understood, it reinforced the idea that more investigation should be given to this aspect.

Thus, LCA modelling provided tools for structuring thinking about what is likely to happen if a development path is followed. It confronted the practitioners with the potential scale of the future technology to inform future developmental decisions. For example, electrowinning was studied more in depth early on and insights were gained into how it might be coupled to the bioleaching process, which inputs would be required and what its potential environmental impact contributions might be.

\subsection{Considering the ambit of bioleaching research and system boundary}

Here, the implications of the choice of system boundary will be explored as a vehicle for discussion of the bioleaching product system. Implicit in the approach of bioleaching research itself was a bounded view of the process, though LCA modelling did require the connection to upstream and downstream contributions to the product system. For the 
optimisation of bacterial processes for maximum yields, progress in the bioleaching of the WEEE research field is focussed on furthering understanding of the bioleaching mechanism, studying how bacteria mediate metal solubilisation from anthropogenic metal-rich waste material. As a starting point for the LCA research, this perspective centred on the bioleaching process was also adopted. It provided a defined starting point with primary data and the cradle (end of life of PCB) to gate (recovered elemental copper) system boundary. A further consideration entailed the function (copper recovery) and the functional unit. Elemental metal recovery had yet to be achieved in the lab, so recovery of cathode copper was chosen as the function to enable later comparison with current technologies. Here, the first conjectures on 'desirable' future development took place. However, this development path, or effectively the scope, was one of many that are possible though it was chosen as the most bounded, also fitting into time constraints.

Taking these issues into consideration, the product system boundary can afterwards be manipulated to take in a full metal cycle scenario from cradle to grave and the compared product systems are then seen from another perspective. In Fig. 1, the bioleaching metal recovery product system and the integrated smelter-refinery product system have been represented within this larger perspective. In this manner, the differences between them become even more accentuated, since the production of secondary copper from PCB happens at different points of the cycle and affects other flows in different ways.

While comparing process technologies and their upstream and downstream flows is in itself illuminating, examining the broader systems in which they operate provides even more insights. The bioleaching product system recovers elemental copper which can go back to the metal product engineering stage. It adds an extra step to the general cycle, but also the possibility of reducing extraction and metal production. The pyrometallurgical system in the best case can incorporate the waste PCB directly back into metal production but currently still relies on flows from extraction. These possible wider systemic changes were not modelled in this research as recycled copper and metals have not been considered going back into the production of PCB. This would be the naturally desired effect of closing the loop and can be broadly considered as beneficial since it offsets the impacts of primary production. Other consequences might be the effects on the current best available technologies involving pyrometallurgy which would also be affected in the long run.

In light of this, the comparison set up in this case study is too narrow for a comprehensive environmental evaluation of the technologies. Conversely, being bound to the bioleaching process, the study was kept manageable. However, having generated this insight at an early stage, it can be taken into account from this point onwards. This suggests that moving between such perspectives and scales is beneficial and the earlier this exploration takes place on the development path, the better. The scope can remain process-focussed to start with as an entry point to this later enlargement of perspective.

\subsection{Options for the role of the emerging technology}

From this point on, a rethinking of the scaled-up scenario of stage 2 can be performed and other useful scenarios can be generated. The position of the future technology can be more effectively considered. Initially, the case study assumed that bioleaching may have to 'compete' with integrated smelter refineries treating WEEE. This perspective inherits the existing standpoint of the metal production industry, which is divided between mining and processing at typically remote locations and multi-product smelter-refineries at industrial sites buying their products. Indeed, bioleaching has been developed at the most distant mining sites to handle lower-grade ores in order to achieve a higher-value product before transportation to smelters.

Leaving this antagonistic perspective aside, the two technologies of smelting and bioleaching may be considered from a synergistic point of view. The combination or integration of the two technologies may be a route to consider. This also does not exclude other functionalities from being incorporated into a much larger metal biodisposal archetype technology. High-grade WEEE is the target of metal recovery in this study, but lower-grade WEEE may also be a future target for these technologies. The effects of changes in the use and demand side of electric and electronic equipment (EEE) making it a reconfigurable technology can affect the economics of metal recovery. Other flows such as the treatment of wastewater, sewage sludge and hazardous waste from municipal solid waste incineration to recover metals may also be considered as a bioleaching feedstock (Lee and Pandey 2012).

At less remote mining operations sufficiently close to areas where WEEE generation takes place, the possibility of combining low-grade ore treatment and WEEE may also be considered. A two-step batch process has achieved high bioleached copper yields from a mix of sulphidic mine waste and ground PCB which has been researched by Guezennec et al. (2014). However, the processing of secondary raw materials for resource recovery is dissimilar to primary ore processing; thus, novel and integrated strategies and recycling routes are needed. It should also be noted that this coupling to resource extraction may originate other significant transportation/logistics flows with a relevant influence on the environmental profile. Additionally, if a slower rate of metal recovery is admissible, then heap bioleaching with all its pros and cons (less process control and greater land use) may also be evaluated instead of continuous stirred tank reactors (CSTRs).

Also, the assumed goal of elemental metal recovery was questioned. In hindsight, a high-value precipitate containing 


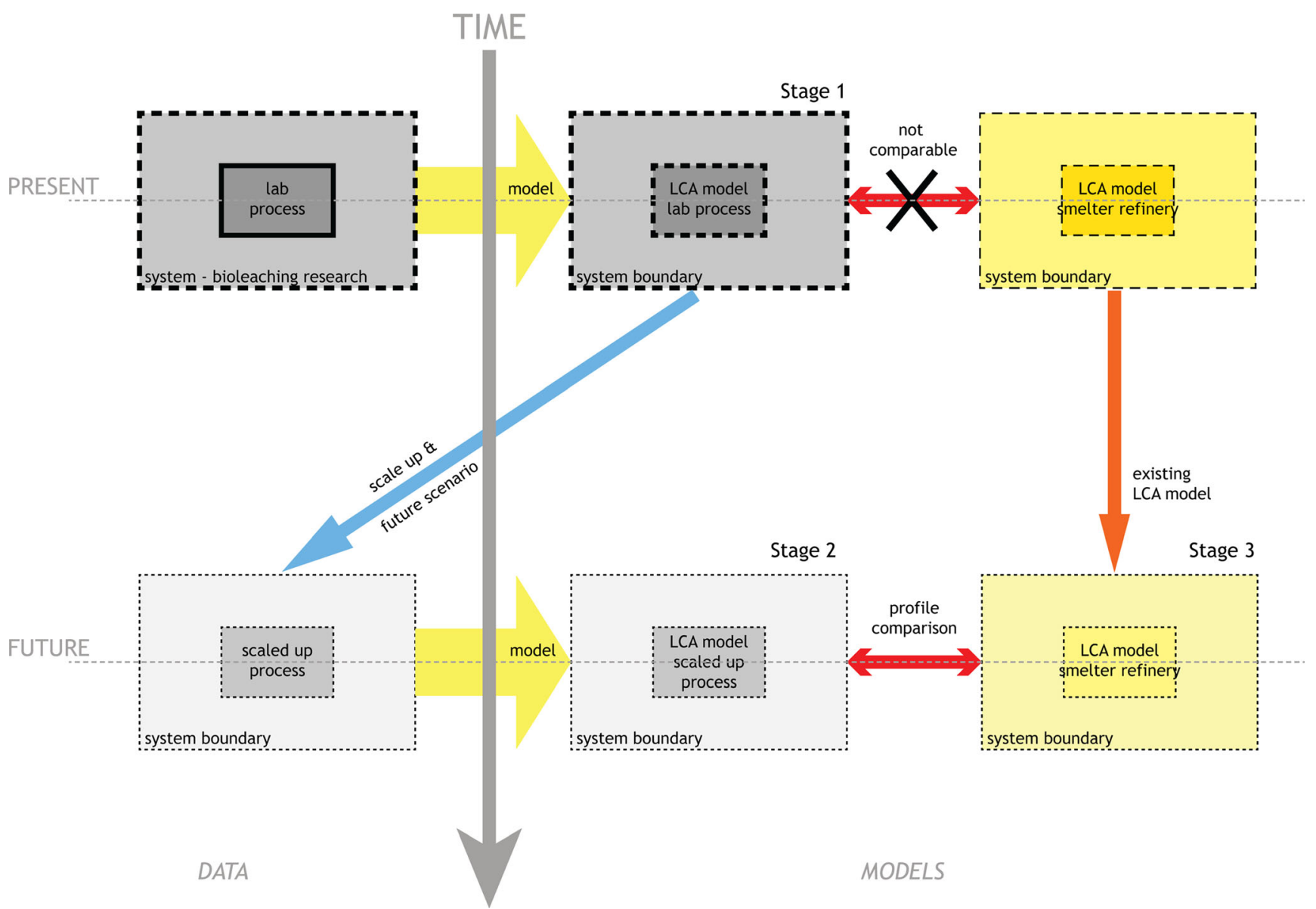

Fig. 1 Schematic diagram of the research stages ex ante LCA and exploratory scenario. Primary data as the starting point is shown on the upper left. Stage 1 LCA modelling of the lab system could not be directly compared with a current industrial technology. Due to the difference in scale, direct comparison is not possible but stage 1 served to define the

the target metal(s) in combination with existing smelter refineries is another development path option to be explored. In the product system modelling, the use stage was considered as a fixed given providing a large short-term generation of WEEE at the end of the lifespan of EEE. The current tendency is indeed for EEE goods to have decreasing lifespans resulting in increased WEEE generation, but this demand side flow may also be reduced. The current evolution of the nature of the goods themselves may also be modified by the enforced application of ecodesign principles (Ongondo et al. 2015). Modular design and design for recycling may make secondary metal recovery more straightforward in the longer term and reduce the demand for sophisticated biohydrometallurgical and pyrometallurgical methods.

Departing from a sequential linear layout of Fig. 2, where recycling loops appear as add-ons, the cyclical representation of Fig. 3 with all of the above ideas can better represent a possible future context and potential interactions of materials and processes in the metal cycle. future scaled-up scenario (bottom left) which then informed scaled-up LCA modelling. This enabled the stage 3 comparison with an integrated smelter refinery. In the diagram, the results generated become more tenuous and uncertain the more we depart from the upper left, the present, going down to the right and speculating about the future

The diversity of perspectives generated by this timely analysis can afford conceptual resilience to a future network of preferably reconfigurable technologies applied to recover metals for the technosphere in the face of resource criticality and more stringent regulation responding to the integration of environmental externalities.

\subsection{Acknowledgement of an exploratory process}

The very issue of a wider system or a wider system boundary would not have been on the research agenda were it not for the application of LCA methodology, where defining one is a specific requirement. This brought a horizon beyond the bioleaching research into view and subsequently afforded the means to make a jump in scale. The whole scaling up and comparison exercise becomes a problem-solution space where an exploratory process can take place: a design process. Ambiguity is essential to it, allowing freedom to manoeuvre 


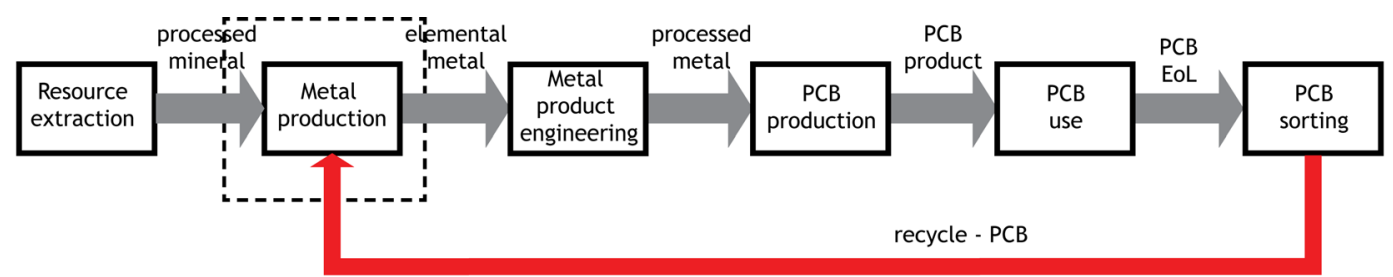

\section{Pyrometallurgical product system}

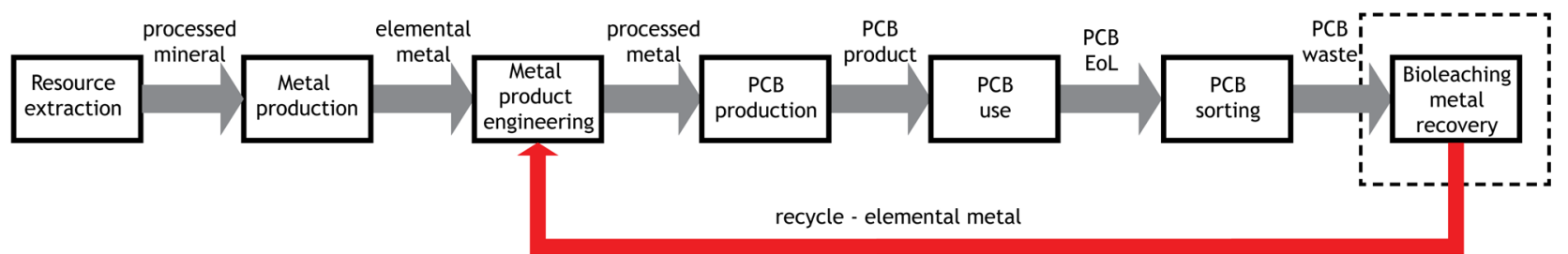

\section{Bioleaching product system}

Fig. 2 Flowcharts of the bioleaching system (below) and pyrometallurgical system for comparison (above) from an expanded full metal cycle perspective. Regarding this wider perspective, the comparability of their metal recovery function comes under question

independently within and beyond potential future scenarios and permitting the reconfiguration of the problem.

The role of LCA as an analytical tool can still be to provide insights into potential environmental profiles within the accepted imprecision but also imposing a kind of order to this ambiguous problem solution space. At this early point in development, dialectical results are the outcome rather than analytical ones, but generated by applying the methodology of
Fig. 3 Cyclical representation of the metal cycle, representing the potential synergies when adopting bioleaching applied to WEEE as part of a networked, integrated system of waste management and resource recovery. Apart from elemental metal recovery from $\mathrm{PCB}$, bioleaching can deliver intermediate metal compounds to smelters for metal production. These are in the metal cycle to process minerals and to recycle separated PCB not viably treated by bioleaching. Bioleaching can also process other inputs for their valuable metal content such as lowgrade mineral ores as well as dust, residues, sludges and slags from metallurgical and manufacturing industries. Wastewater, sewage sludge and fly ash are also potential inputs to bioleaching, contributing to recycling of resources and pollution mitigation

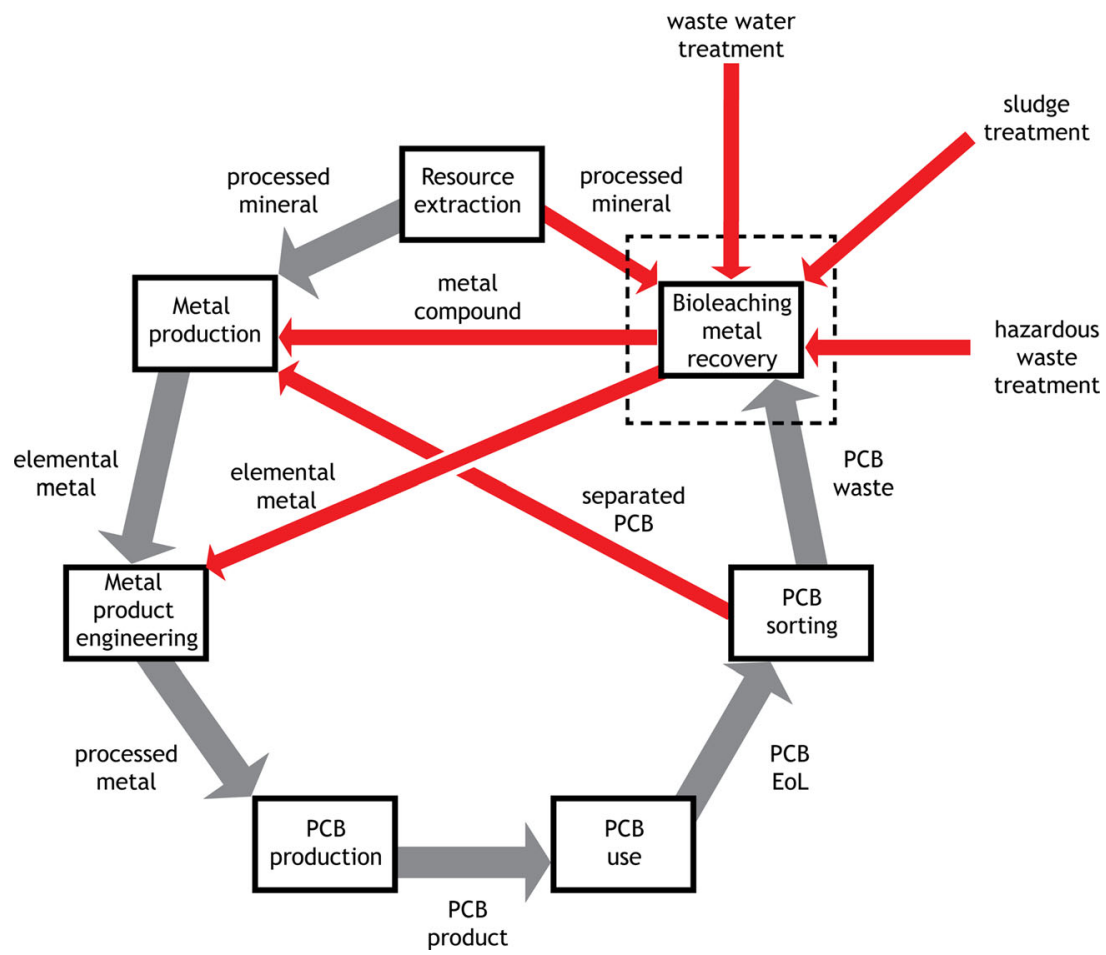


an analytical tool. The imprecise quantitative results generated were a necessary component of this exploration, allowing analysis of upstream contributions. The question arises of whether comparable knowledge might be obtained without the full quantitative application of LCA and only some general principles from the framework. The efforts of conjecture and estimation to fulfil the prescribed quantitative side of the LCA framework certainly do provide necessary extra depth to the resulting early insights on technological scales, regardless of the numerical results' lack of accuracy.

Figure 4 is a representation of the typical development path of a technology and the amount of knowledge, costs, degrees of freedom and environmental impacts associated with it, also showing instances of life cycle assessment along the path at the top. The LCAs carried out in this case study take place at a moment in time at the left of the diagram during the experimental stage of development. The potential environmental impacts are represented within a band of values, which typically become narrower along the development path with increasing knowledge and decreasing uncertainty. However, for an ex ante scaled-up LCA with scenario, the band of outcomes remains broad and uncertain (shown in the lighter area). Despite uncertain outcomes after carrying out the ex ante LCAs, it can be said that the climbing section of the knowledge curve has been shifted to the left. Also, such increased foresight may allow a positive influence on the cost curve (flatter) and more adaptiveness vis-a-vis the degrees of freedom of development.

\subsection{Incisive developmental design tool}

The prospective exercise of the case study displays a possible design tool that introduces information and knowledge earlier in the development process. The sooner the researcher(s) move(s) through the learning curve and engage(s) with relevant issues, the faster the insights can be understood. The further down the development path these insights are encountered, the less room for manoeuvre. The potential temporal
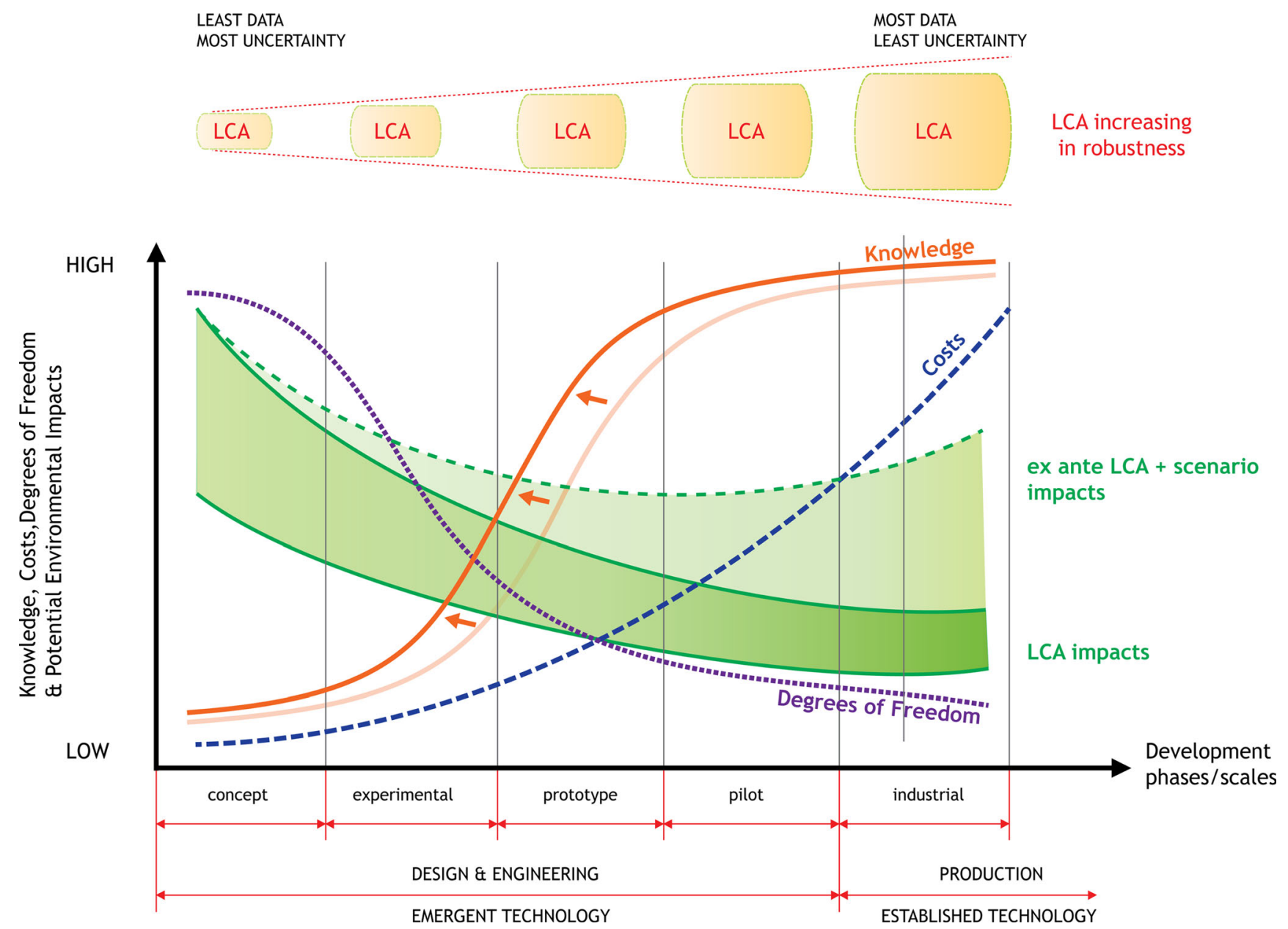

Fig. 4 Idealised diagram of technology development related to LCA, showing how knowledge costs, degrees of freedom and potential environmental impacts vary over the development phases. Despite uncertainties, the knowledge curve can be considered to shift to the left after ex ante LCA and exploratory scenario application, illustrating the gaining of new insights to inform further technology development (composite diagram derived from Hetherington et al. 2013, Hummen and Kästner 2014 and Zschieschang et al. 2012) 
linkages can be appreciated, and the consequences of decisions that may constrain or promote future options can be acknowledged. These findings can inform the development process and improve the quality of later refinements of the LCA of the technology. Support for decision-making capability is pushed earlier down the development cycles, potentially enabling a quicker, more prescient response.

The question of whether such front loading of information may be an overload for the practitioner(s) arises. The practitioner must have the multidisciplinary expert capacity to take this informational baggage on board and also enough understanding to disregard any unnecessary data. This desirable expertise may only accompany a greater experience of practitioners and the gradual establishment of an accepted body of collective knowledge over time.

\subsection{Regarding LCA in a different way}

If regular LCA can be criticised for the high degree of subjectivity and roughness of the modelling of reality, then in such an ex ante application coupled with an exploratory scenario this is clearly even more so. The value of such a study and its application lie elsewhere. It does not deliver a valid assessment but raises more strategic questions and suggests more possible constraints. It contributes very well to the problemsolution space. What Schön (1995) calls the dilemma of rigour or relevance regarding problems was exemplified by this case study where the weight of relevance of the understanding gained displaced the reduced accuracy of the results. Here, rigour alludes to manageable problems that lend themselves to solution through the use of research-based theory and technique. Relevance refers to messy and confusing problems intractable to technical solutions.

The function of ex ante LCA can act as a wedge at the beginning of the development of a novel technology to introduce systemic perspectives and environmental concepts into the domain of the investigation, generating another kind of knowledge. Moreover, the expectations of researchers are influenced with a more nuanced attitude regarding future promises and the validation of knowledge claims related to environmental impacts. The expectations of researchers, manifesting their reaching out for future lucidity, are as important as the actual production of results and the validation of knowledge claims. Sennett (2008) terms this prehension, a grasping to anticipate meaning, without waiting until all the information is available. Prehension signals alertness, engagement, and risk-taking all in the act of looking ahead.

This could be termed open life cycle analysis (OLCA) or life cycle aided technology development (LCATD). There arises a perception that with such a case study one has gone so far forward along a development path in search of insights about the future, that the nature of the issues involved has been transformed. While potential environmental hotspots and the developmental challenge for the novel technology are given definition, the research domain as a whole has been infused with a systems perspective.

This then may raise the question of where along the development path is the (blurred) boundary when 'ex ante' does transform into 'regular' LCA. Arguably given the current methodological criticisms of LCA, there is never a transition to a 'true' LCA even when there is an abundance of quality data defining a product system. The development curves in the diagram are idealisations, so even if knowledge increases or becomes richer it may be accompanied by unexpected increased uncertainties in other areas.

Applying seemingly imperfect scientific instruments is a speculative undertaking. Practitioners are obliged to engage in reflective practice, as a 'conversation with the materials of a situation' (Schön 1984). It is demanding, but straightforward to do. It stimulates imaginative processes and assists the practitioner in becoming more attuned to tackling problems. As a result, from experimentation with this dissonance, new findings can spring from such tensions. Ambiguity and resistance can be instructive, and such experiences should be accepted (Sennett 2008).

\subsection{Position relative to other approaches}

The value of applying the rigour of LCA at the early stage is acknowledged by Wender et al. (2014a, 2014b), the proponents of anticipatory LCA. Anticipatory LCA proposes an overarching framework to incorporate a broad stakeholder involvement, integration of risk assessment and tools to support decision-making. Anticipatory LCA does not seek to create a realistic model but rather to expand uncertainty and perform global sensitivity analysis to identify the most environmentally promising research agendas. Its emphasis appears to be on broader research policy and strategy with a broadening of tasks and responsibilities of the diverse actors across the technology life cycle. This is certainly applicable to cuttingedge innovative technologies developed by large R\&D consortia made up of a large cohort of interdisciplinary participants.

However, this is an optimal research situation with many contributors, whereas this study was more academic, bounded and compact with no stakeholder involvement. Nonetheless, it aligned with anticipatory LCA in its general philosophy to target responsible innovation. This case study was necessarily a less comprehensive and time-constrained application of prospective LCA, with a similar aim to use LCA for what it can deliver to prepare for the future, not to predict it. It attempted to maximise the bounded expertise of the practitioners by adopting the spirit of anticipatory LCA striving for an interdisciplinary approach/mindset throughout.

Though there are some parallels in the use of proxies, it also differs from the approach of Tecchio et al. (2015) which scaled 
up a chemical production process of a novel substance for LCA by modelling a similar substance at the pilot scale and adapted the results using data simulated applying chemical and thermodynamic principles. This technique is quite product- and process-specific and relies on real piloting. Here, the relevance of the nature of the product, service or technology as well as the level of development of the technology are also highlighted. This bioleaching case study, including a difficult to predict biological component, the bacteria and their metabolic products, relied on proxy technologies and is at an earlier stage than piloting.

\subsection{Database and modelling recycling}

Finally, at the more procedural level of the LCA framework, it was seen that many unit processes in databases are heterogeneous, depending on empirically aggregated phenomenological data from various sources, taking a black box approach. Also, the way processes are modelled in the database does not allow breaking them open easily to recycle between unit processes and close loops. Some services (e.g. waste treatment) are modelled as an integrated process that can be conveniently connected to a unit process as an economic inflow. However, recursive loops of secondary materials are not modelled by these service processes. This convenience also does not allow straightforward recycling and raises questions on whether any flows are being modelled as recycled or safely disposed. The increase of recycling means that this should be addressed in the database modelling.

\section{Conclusions}

The added inconsistencies and uncertainties of this approach mean that the regular legacy LCA framework cannot be applied with the same goal in such an ex ante situation. A rigorous environmental assessment cannot be expected at such an early stage. An ex ante context for LCA does not permit reaching an environmental assessment which can be considered an accurate result. The ex ante context is a fluid design space at the start of development, not yet mature and must be treated as so. Use of outcomes outside this context can only be made with high reservations. However, such outcomes serve as a useful foundation to be built upon. The value lies not so much about what is discovered but about how this may inform what can be learned in the following stages.

The powerful combination of a 'hard' analytical tool with a 'soft' exploratory method makes connections, provides more context and amplifies perspectives. A scaffold is set up to structure an incipient state of development within which to consider options. The approach adds an external perspective to broaden, organise and discover the particular features of the early stage situation and, from their gradual discovery, constructs a preliminary proposal, a mock-up development, to be studied for further understanding of the situation. In doing so, early scrutiny of the emerging technology is facilitated. Background systems are brought to the fore, and how technologies are viewed and compared is considered in a future-oriented way. In so doing, prescience, foreknowledge and foresight are advanced. The first tool, LCA, stimulates conscientious research and questioning to construct a viable map of a product system within the technosphere, while the second, scenario application, promotes thinking into the future. Higher-order learning comes about, where reflection on the knowledge gained to inform future action occurs. It is induced at a timely moment in the development process when it can be of greatest influence. Ex ante LCA challenges the research domain and the practitioner's understanding of it. The LCA framework is supposed to be intrinsically iterative, but it can also be linked to technological development, revisited at each phase in parallel as an integral part of it. Not taking LCA as a one-off diagnosis but part of the problemsolution space of technological development can establish feedback loops between the product system under study and the scenario(s) and LCA, which can be developed together.

The diagram of Fig. 5 summarises the problem-solution space generated by the case study. The problem-solution space is complex and laden with ambiguity, yet engaging with it at every step can enlighten LCA practitioners and technology developers with new understanding.

The ex ante LCA and scenario tandem approach brings a systematic rigour and discipline to an ambiguous situation and promotes exploration. It can be envisaged as an advance environmental screening tool applied in research and industry and even further forward in a conceptual R\&D context. This suggests an even more precocious application where it can also be used to evaluate research proposals or design concepts themselves. Such applications can also provide key contributions to evaluate the viability of early-stage studies on closing material loops and desirable transitions to a circular economy.

\section{Recommendations}

Though accepting that ex ante LCA is a broader, more open, less structured and quantitative approach than traditional LCA, more estimative aspects can be focussed upon as its inputs. To develop the estimative quality of the modelling, simulations used to design product systems can be targeted for inclusion in LCA. For estimative, exploratory ex ante LCA, another type of more fundamental database based on increasing understanding of physical and chemical processes of material and energy properties can be envisaged. Existing simulation software using automation and parametrisation can be co-opted to obtain necessary speculative information on how materials can be combined, how they react and how they 


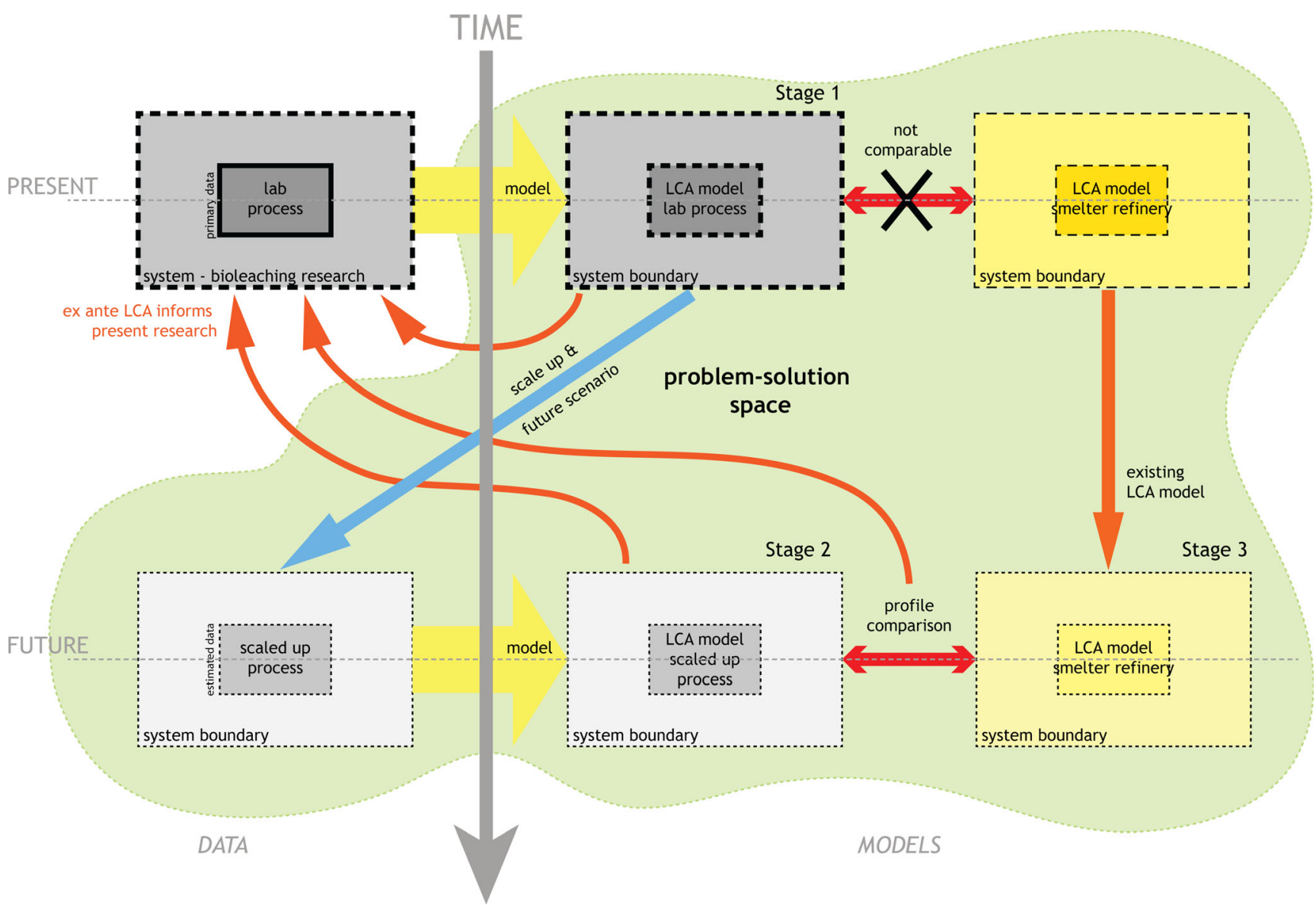

Fig. 5 The three stages of the application of ex ante LCA and the exploratory scenario inform the present research adding new insights to the research domain

can be separated. This modelling software could also process fluid flows, heat transfer, mass transfer and thermodynamic and mechanical processes and couple them to LCA to arrive at potential environmental impacts. Here, the issue of data can also be no less of a challenge. This approach also relies on increased engineering design skills and experience of the practitioner(s). These valuable estimative linkages should be kept visible. Indeed, they should be traceable and not hidden under an interface or inscrutable code and calculations. Another focus could be a system-based perspective at the outset concentrating on the fulfilment of a societal function rather than a process-based one looking at the functioning of the technology.

A similar sort of exercise could be incorporated into the training of scientific researchers, engineers and designers. Such disciplines can benefit from such exposure to working with early broad quantifications on energy inputs and how they are generated, mapping of product systems and production cycles, the origin of material inputs and the grasp of scales in which their (future) projects may be embedded. Also the idea that the values that make up an environmental profile are not absolutes can be promoted. Owing to uncertainties and model limitations one must always speak of potential environmental impacts. Applied in this manner, LCA should not be regarded as a quantitative engineering tool to be used in a formulaic fashion.

This case study also points to a preliminary model for reorganising how research is carried out. A different division of tasks and way of interacting to better integrate the performance of researchers and think farther into the future can be created. Instead of working in isolation in departments, disciplines should be mobilised to promote more effective multidisciplinarity. Different researchers work in collaboration, as in this small-scale case study, to purposely widen perspectives, stimulate and cross fertilise understanding and better anticipate the consequences of decisions on the research and development path. In this way, effective pathways for sustainable development can be identified early on, above all avoiding unsustainable pathways that are based on limited and selective perspectives. Where time and means are not available to include broad stakeholder perspectives, this can also serve as the guiding mindset of the researcher, engineer or designer. Ex ante LCA promotes investigation and sensitivity to the context or wider system. The advancement of this other type of LCA geared to this purpose may subsequently be explicitly targeted. 
It is too hasty to attempt to distil any universals from this case study due to the temporal aspect. It has been executed with bioleaching of e-waste still in the lab at the level of proof of concept. Further development has yet to take place. So far, only its influence at the problem definition stage within the problem solution space has been discussed. It also has some singular characteristics that make generalisation difficult. For instance, other technologies may be more novel and require a more speculative approach with regard to their possible future contexts. In such cases, less data would be available and would lean much more on estimations and expert opinion. It is highly likely that any quantified results are erroneous being invalidated by oversimplification or the failure to make considerations of essential importance. This uncertainty is openly acknowledged, but it is hoped that the path illustrated will enable others to reach other ex ante LCA domains quicker and more conveniently.

The potential usefulness of applying ex ante LCA to technology development has been discussed. An exploratory scenario and LCA allow the systematic gathering of information influenced by interpretations, choices and judgements of the practitioner to build a preliminary construct showing possible relationships and patterns beyond the process itself. For a more grounded general approach, other attempts at similar ex ante LCA by other practitioners are required to establish an evidence base and longer-term evaluation of possible influence on the following cycles of technological development. Then, a range of possible aspects of comparability may be established. If validated by more research, the systems focus can also be expanded to include anticipatory assessment of economic and social aspects.

Open Access This article is distributed under the terms of the Creative Commons Attribution 4.0 International License (http:// creativecommons.org/licenses/by/4.0/), which permits unrestricted use, distribution, and reproduction in any medium, provided you give appropriate credit to the original author(s) and the source, provide a link to the Creative Commons license, and indicate if changes were made.

\section{References}

Ambrose G, Harris P (2009) Basics design 08: design thinking. AVA Publishing, Lausanne

Andreasen MM (1991) Design methodology. J Eng Design 2:321-335. doi:10.1080/09544829108901689

Andreasen MM (2011) 45 Years with design methodology. J Eng Des 22: 293-332. doi:10.1080/09544828.2010.538040

Arthur WB (2007) The structure of invention. Res Policy 36:274-287. doi:10.1016/j.respol.2006.11.005

Attero website (2015) Attero webpage. Our waste-to-energy plants. http://www.attero.nl/en/our-waste-to-energy-plants/moerdijk/. Accessed 15 Apr 2015
Biswas AK, Davenport WG (2011) Extractive metallurgy of copper, 5th edn. Elsevier Ltd, Oxford

Boothroyd G, Dewhurst P, Knight W (2000) Product design for manufacture and assembly, 2nd edn. Marcel Dekker Inc., NY

Brandl H, Bosshard R, Wegmann M (2001) Computer-munching microbes: metal leaching from electronic scrap by bacteria and fungi. Hydrometallurgy 59:319-326. doi:10.1016/S0304-386X(00 )00188-2

Brierley CL, Brierley JA (2013) Progress in bioleaching: part B: applications of microbial processes by the minerals industries. Appl Microbiol Biotechnol 97:7543-7552. doi:10.1007/s00253-0135095-3

Caduff M, Huijbregts MAJ, Koehler A et al (2014) Scaling relationships in life cycle assessment. J Ind Ecol 18:393-406. doi:10.1111 jiiec. 12122

Cinelli M, Coles SR, Kirwan K (2014) Analysis of the potentials of multi criteria decision analysis methods to conduct sustainability assessment. Ecol Ind 46:138-148. doi:10.1016/j.ecolind.2014.06.011

Clavreul J, Guyonnet D, Christensen TH (2012) Quantifying uncertainty in LCA-modelling of waste management systems. Waste Manag 32: 2482-2495. doi:10.1016/j.wasman.2012.07.008

Cross N (2005) Engineering design methods: strategies for product design, 4th edn. Wiley, Chichester

Cross N (2011) Design thinking. Understanding how designers think and work. Berg Publishers. Bloomsbury Publishing Plc, NY

Cross N, Roozenburg N (1992) Modelling the design process in engineering and in architecture. J Eng Design 3:325-337. doi:10.1080 /09544829208914765

Dewulf W, Willems B, Duflou JR (2006) Estimating the environmental profile of early design concepts. Innovation in Life Cycle Engineering and Sustainable Development 321-334

Dorst K, Cross N (2001) Creativity in the design process: Co-evolution of problem-solution. Des Stud 22:425-437. doi:10.1016/S0142-694 $\mathrm{X}(01) 00009-6$

Duflou JR, Dewulf W (2005) Eco-impact anticipation by parametric screening of machine system components an introduction to the EcoPaS methodology. Product Engineering: Eco-Design, Technologies and Green Energy 17-30. doi: 10.1007/1-40202933-0 2

Erüst C, Akcil A, Gahan CS et al (2013) Biohydrometallurgy of secondary metal resources: a potential alternative approach for metal recovery. J Chem Technol Biotechnol 88:2115-2132. doi:10.1002 jectb.4164

Frischknecht R, Büsser S, Krewitt W (2009) Environmental assessment of future technologies: how to trim LCA to fit this goal? Int J Life Cycle Assess 14:584-588. doi:10.1007/s11367-009-0120-6

Gavankar S, Suh S, Keller AA (2015) The role of scale and technology maturity in life cycle assessment of emerging technologies: a case study on carbon nanotubes. J Ind Ecol 19:51-60. doi:10.1111 /jiec. 12175

Graedel TE, Allenby BR (2010) Industrial ecology and sustainable engineering, Int. Ed. Prentice Hall, Upper Saddle River, NJ

Guezennec AG, Bru K, Jacob J, d'Hugues P (2014) Co-processing of sulfidic mining wastes and metal-rich post-consumer wastes by biohydrometallurgy. Miner Eng 33:45-53. doi:10.1016/j. mineng.2014.12.033

Guinée JB, Gorrée M, Heijungs R et al. (2002) Handbook on life cycle assessment. Operational guide to the ISO standards. Kluwer Academic Publishers

Guinée JB, Heijungs R, Huppes G et al (2011) Life cycle assessment : past, present, and future. Environ Sci Technol 45:90-96

Haupt G (2014) Learning from experts: fostering extended thinking in the early phases of the design process. Int $\mathrm{J}$ Technol Des Educ. doi:10.1007/s10798-014-9295-7

Hennebel T, Boon N, Maes S, Lenz M (2015) Biotechnologies for critical raw material recovery from primary and secondary sources : R \& D 
priorities and future perspectives. New Biotechnol 32:121-127. doi:10.1016/j.nbt.2013.08.004

Henriksson PJG, Guinée JB, Heijungs R et al (2013) A protocol for horizontal averaging of unit process data - including estimates for uncertainty. Int J Life Cycle Assess 19:429-436. doi:10.1007 /s11367-013-0647-4

Hetherington AC, Borrion AL, Griffiths OG, McManus MC (2013) Use of LCA as a development tool within early research: challenges and issues across different sectors. Int J Life Cycle Assess 19:130-143. doi:10.1007/s11367-013-0627-8

Höjer M, Ahlroth S, Dreborg K-H et al (2008) Scenarios in selected tools for environmental systems analysis. J Clean Prod 16:1958-1970. doi:10.1016/j.jclepro.2008.01.008

Hospido A, Davis J, Berlin J, Sonesson U (2009) A review of methodological issues affecting LCA of novel food products. Int J Life Cycle Assess 15:44-52. doi:10.1007/s11367-009-0130-4

Hummen T, Kästner F (2014) Evaluating existing methodological approaches for prospective LCA at early technology development stages. In: LCA XIV San Francisco Proceedings from the LCA XIV International Conference, American Center for Life Cycle Assessment, San Francisco, pp 19-30, 6-8 October 2014

Ilyas S, Lee J (2014) Bioleaching of metals from electronic scrap in a stirred tank reactor. Hydrometallurgy 149:50-62. doi:10.1016/j. hydromet.2014.07.004

International Organisation for Standardization (ISO) (2006) ISO 14044 Environmental management-life cycle assessment - requirements and guidelines. Switzerland, Geneva

Issildar A, van de Vossenberg J, Rene ER et al (2015) Two-step bioleaching of copper and gold from discarded printed circuit boards (PCB). Waste Manag. doi:10.1016/j.str.2014.12.012

Jeswiet J, Hauschild M (2005) EcoDesign and future environmental impacts. Material Design 26:629-634. doi:10.1016/j. matdes.2004.08.016

Korevaar G (2004) Sustainable chemical processes and products. New design methodology and design tools. PhD thesis. Delft University of Technology

Lee J-C, Pandey BD (2012) Bio-processing of solid wastes and secondary resources for metal extraction - a review. Waste Management (New York, NY) 32:3-18. doi: 10.1016/j.wasman.2011.08.010

Neale JW, Robertson SW, Muller HH, Gericke M (2009) Integrated piloting of a thermophilic bioleaching process for the treatment of a low-grade nickel-copper sulphide concentrate. J South Afr Inst Min Metall 109:273-293. http://www.scielo.org.za/scielo. php?script=sci arttext\&pid=S0038-223X2009000500002\&lng= en\&nrm=iso. Accessed 26 Jan 2017

Nielsen P, Wenzel H (2002) Integration of environmental aspects in product development: a stepwise procedure based on quantitative life cycle assessment. J Clean Prod 10:247-257. doi:10.1016/S09596526(01)00038-5

Nijhuis S (2011) Visual research in landscape architecture. Research in Urbanism Series 2:103-145

Ongondo FO, Williams ID, Cherrett TJ (2011) How are WEEE doing? A global review of the management of electrical and electronic wastes. Waste Manag 31:714-730. doi:10.1016/j.wasman.2010.10.023

Ongondo FO, Williams ID, Whitlock G (2015) Distinct urban mines : exploiting secondary resources in unique anthropogenic spaces. Waste Manag 45:4-9. doi:10.1016/j.wasman.2015.05.026

Oxman RE (1994) Precedents in design: a computational model for the organization of precedent knowledge. Des Stud 15:141-157. doi:10.1016/0142-694X(94)90021-3
Piccinno F, Hischier R, Seeger S, Som C (2016) From laboratory to industrial scale: a scale-up framework for chemical processes in life cycle assessment studies. J Clean Prod 135:1085-1097. doi:10.1016 /j.jclepro.2016.06.164

Reap J, Roman F, Duncan S, Bras B (2008) A survey of unresolved problems in life cycle assessment. Part 2: impact assessment and interpretation. Int J Life Cycle Assess 13:374-388. doi:10.1007 /s11367-008-0009-9

Rocchetti L, Vegliò F, Kopacek B, Beolchini F (2013) Environmental impact assessment of hydrometallurgical processes for metal recovery from WEEE residues using a portable prototype plant. Environ Sci Technol 47:1581-1588. doi:10.1021/es302192t

Schön DA (1995) The new scholarship requires a new epistemology. Change: The Magazine of Higher Learning 27:26-34. doi:10.1080 /00091383.1995.10544673

Schön DA (1984) The reflective practitioner. Basic Books, USA

Sennett R (2008) The craftsman. Penguin Books, London

Shibasaki M, Albrecht S, Kupfer T (2007a) Small scale and large scale plants - effect on life cycle assessment. In: Plesu V, Agachi PS (eds) 17th European Symposium on Computer Aided Process Engineering - ESCAPE17. Elsevier B.V., pp 1-6

Shibasaki M, Fischer M, Barthel L (2007b) Effects on life cycle assessment - scale up of processes. In: Advances in life cycle engineering for sustainable manufacturing businesses. Proceedings of the 14th CIRP Conference on Life Cycle Engineering, Waseda University, Tokyo, Japan, June 11th-13th, 2007., 1st edn. Springer, London, pp 377-381

Shibasaki M, Warburg N, Eyerer P (2006) Upscaling effect and life cycle assessment. LCE 2006:61-64

Simon HA (1969) The sciences of the artificial, 3rd edn. MIT Press, Cambridge, Massachusetts

Tecchio P, Freni P, De Benedetti B, Fenouillot F (2015) Ex-ante life cycle assessment approach developed for a case study on bio-based polybutylene succinate. J Clean Prod. doi:10.1016/j. jclepro.2015.07.090

Tischner U, Masselter S, Hirschl B (2000) How to do EcoDesign? A guide for environmentally and economically sound design. Verlag form: Frankfurt am Main

Vera M, Schippers A, Sand W (2013) Progress in bioleaching: fundamentals and mechanisms of bacterial metal sulfide oxidation-part a. Appl Microbiol Biotechnol 97:7529-7541. doi:10.1007/s00253-0134954-2

Villares M, Ișıldar A, Beltran AM, Guinee J (2016) Applying an ex-ante life cycle perspective to metal recovery from e-waste using bioleaching. J Clean Prod 129:315-328. doi:10.1016/j. jclepro.2016.04.066

Wender BA, Foley RW, Hottle TA et al (2014b) Anticipatory life-cycle assessment for responsible research and innovation. Journal of Responsible Innovation 1:200-207. doi:10.1017 /CBO9781107415324.004

Wender B, Foley RW, Prado-López V et al (2014a) Illustrating anticipatory life cycle assessment for emerging photovoltaic technologies. Environ Sci Technol 48:10531-10538

Zschieschang E, Pfeifer P, Schebek L (2012) Modular Server - Client Server (MSCS) approach for process optimization in early R\&D of emerging technologies by LCA. In: Leveraging Technology for a Sustainable World. Springer Berlin Heidelberg, pp 119-124. doi:10.1007/978-3-642-29069-5 21 